\title{
Grand challenges in diabetes
}

\author{
Aaron Vinik* \\ Department of Medicine, Division of Endocrinology and Metabolism, Eastern Virginia Medical School, Norfolk, VA, USA \\ *Correspondence: vinikai@evms.edu
}

The magnitude of the diabetes epidemic from its macrovascular (including heart attacks, strokes, and peripheral vascular disease) and the microvascular complications of diabetes (including retinopathy, nephropathy, neuropathy, and disorders of the integument and bone) - cannot be underestimated. In the US alone, an estimated 25.8 million people have diabetes, primarily Type 2 . In 2010, 1.9 million new cases were diagnosed in people age 20 or older, amounting to more than 3500 each day. One in three children born today will become diabetic, and there are 79 million people in the US alone who are prediabetic. Complications of diabetes are a major cause of mortality and morbidity. Each year, diabetes contributes to 224,000 deaths, 96,000 amputations, or 1 amputation every $10 \mathrm{~min}$ in the US; 44,000 begin treatment for kidney failure; $12,000-24,000$ become blind; and the cost is becoming overwhelming. In 2007 , the cost was $\$ 178$ billion, of which medical expenditures was $\$ 116$ billion, with the indirect costs from loss of productivity estimated at $\$ 58$ billion. Globally in 2003, there were 194 million and this is expected to increase by 2025 to 333 million - a $72 \%$ increase. The hardest hit is Asia with an expected increase of $106 \%$. To what can we attribute this explosion, clearly the diabetes explosion is following closely on the heels of the obesity pandemic. The LOOK AHEAD study has taught us that a healthy lifestyle can reduce the metabolic consequences of obesity (Wing et al., 2011), but it is naïve to think that this will deal with the global problem. What is needed are efforts to involve the legislators at city, state, nationally, and globally to find novel approaches to stemming this tide. In the meanwhile, a greater in-depth probing of the mechanisms of surgical approaches to reduction of calorie intake should surely lead to novel therapies for medically altering this landscape and for reducing the need for expensive and brutal surgery to counter a social disaster. The essential component of lifestyle management of obesity and diabetes is a change in physical activity, which unfortunately is an anathema to most people and a leading cause of diabetes and obesity. We need innovative and creative, fun activities as surrogates to replace the traditional "exercise." Physicians and health professionals should act as role models engaging in enjoyable physical activities with achievable goals and with social and physiological benefits. However, there clearly is a lesson to be learned from the fact that only about $30-40 \%$ of obese people develop type 2 diabetes although $80-90 \%$ of type 2 diabetics are obese. What affords certain people this protection? Clinical and genetic risk factors identified in the Malmo study for this susceptibility include (HR): time period for either men or women (1.74), a first degree family history of diabetes (1.65), current smoking (1.39), increased body-mass index (per 1 SD, 1.49), increased fasting or $1 \mathrm{~h}$ postprandial plasma glucose (per $1 \mathrm{SD}, 1.51$ ), increased diastolic blood pressure (per $1 \mathrm{SD}, 1.16$ ), increased triglycerides (per 1SD, 1.28), increased y-glutamyltransferase (per 1 SD, 1.10), increased alanine aminotransferase (per 1 SD, 1.37). So the question arises: "Are there no guaranteed risk predictors which need to be sought energetically, perhaps allowing an earlier window of opportunity in prevention of progression?" Genetic studies of predisposition to $\mathrm{T} 2 \mathrm{D}$ have now unearthed a combination of the risk alleles in 11 SNPs, and there are MODY genes which transmit the condition as an autosomal dominant - yet we can only account for $<0.5 \%$ of the predisposition genetically. We need to do better and make a concerted effort, particularly now that we have the human genome in hand. An alternate to behavioral and genetic approaches is to address the mechanistic aspects of the different forms of diabetes. In type 1 diabetes, we now have an understanding of the genetic predisposition to autoimmune destruction of the pancreatic beta cells, the role of precipitating events, and how it ultimately devolves around a loss of beta cell mass and failure of islet regeneration by islet neogenesis or replication While there are agents that enhance neogenesis from proto-differentiated stem cells resident in the pancreas such as INGAP, the appropriate agents to curb the vicious inflammatory autoimmune attack have thus far escaped discovery. The gap between genomic stem cells, which, although promising, have yet to fulfill their promise, and alternative strategies using bone marrow or adipose tissue derived stem cells should receive greater attention as prospective therapies (Power and Rasko, 2011). There is a need to recapitulate fetal ontogeny, but there are elusive critical factors. However, the demonstration that adult stem cells can be reprogrammed ex vivo and tailored to generate the specific cells of interest is very encouraging. Our particular interest in this area has been using plasmids containing the genes of interest and injecting these into muscle or skin by electroporation, thereby creating a stable reproducing form of the gene of interest and its products. Similar approaches are likely to yield rewarding new therapeutic options. Furthering the understanding of the genetics and role of autoimmune mechanisms in type 1 diabetes and the genetics of type 2 diabetes are therefore topics of particular interest.

Inflammation is the buzz word of this decade. It seems that we can now attribute to inflammation a role in atheroma, beta cell destruction and even the microvascular complications of diabetes. What is not clear is whether this is a cause of the disorder, exerts a pathogenic role, or is simply an innocent bystander and a consequence of the events that occur in all these different tissues. Mechanistic studies and a search for appropriate anti-inflammatory agents - of which none have shown a modicum of success - should not escape our attention!

In the treatment of diabetes, we have come a long way from the once dearth of agents that at one time included only insulin, sulfonylureas and the biguanides. Today, we have a plethora of agents addressing the "ominous Octet" of dysfunction referred to 
by Dr. DeFronzo involving the liver, pancreas, adipose tissue, and musculoskeletal system and the recent additions of gastrointestinal, renal, and brain contributions to dysmetabolism. Thus, we need better study designs, carried out over long time periods in appropriate species - but we cannot afford to overlook the statistics. Less than one third of patients with diabetes are at their management targets of their glycemic control, a number which plummets further to $<7 \%$ if one includes the goals for hypertension and dyslipidemia that accompany type 2 diabetes. So why is this? Challenges in achieving goals are myriad (Donnan et al., 2002; McDonald et al., 2002; Van Gaal and De Leeuw, 2003; Brown et al., 2004; Blonde, 2005; Osterberg and Blaschke, 2005; Shah et al., 2005; Bergenstal, 2006; Vinik, 2007; Rakel, 2009):

- Clinical inertia of physicians, titration is a tardy task

- Suboptimal use of available therapies

- Failure to combine drugs targeting all core defects of type 2 diabetes

- Potential for increased side effects with use of multiple agents

- Fear of hypoglycemia and weight gain

- Suboptimal adherence to lifestyle measures

- Underuse of medications as a result of - Cost

- Complexity of therapy

- Patient provider relationship

The fear of hypoglycemia and weight gain should lead to better and newer agents including different forms of insulin, the incretin mimetics and the DPP1V inhibitors which, for the most part, only stimulate insulin production depending upon the prevailing glucose level and thus per se do not cause hypoglycemia (Nathan et al., 2009). The findings that hypoglycemia may be a marker for a much greater defect in metabolic counter-regulation should be an incentive to further understand the nature of the meaning of hypoglycemia and its consequences, as well as attempts to rectify them (Zoungas et al., 2010).

With the advent of modern technologies, we ought to be able to circumvent this apathy and lethargy of aggressive early treatment. Both the DCCT and the UKPDS (Holman et al., 2008) taught us that early investment is rewarded with good meta- bolic memory, conferring a reduction in the complications despite later loss of glycemic control. Understanding this mechanism will inevitably change the way we deal with management issues. The alternate is certainly not attractive. Three major studies - ADVANCE, ACCORD, and VADT taught us that intensification of glycemic control in people at great risk for macrovascular complications does not achieve a reduction in major adverse cardiovascular events (MACE; Boussageon et al., 2011; Bennett et al., 2012). Indeed, the increase in sudden death of $22 \%$ in the ACCORD study certainly got the attention of clinicians. The factors increasing this bad legacy created a need for circumspection in the management of people with longstanding diabetes, African Americans, women, people with impaired renal function, proteinuria and, surprisingly, people with numb feet and autonomic dysfunction. Development of risk stratification and elucidating the pathogenesis of bad legacy will be a great change for basic and clinical researchers and allow widening of the therapeutic window and remove the fear of being aggressive because it simply is too late. A take-home message from the ACCORD study is the role of loss of autonomic balance as a factor conducive to risk of cardiovascular events. Autonomic neuropathy has long been the Cinderella of the complications of diabetes despite the fact that it has repeatedly been shown to increase the risk of sudden death by a HR of 3.48 if there is more than one abnormality. As pointed out by (Vinik et al., 2011), the combination of peripheral neuropathy and autonomic dysfunction confers a HR for events of 4.33, perhaps the greatest risk we have witnessed in recent years. This is what energized me to submit the lead article on the role of neuro-inflammation and the brain as the conductor of the endocrine orchestra and the possible role of a cholinergic anti-inflammatory reflex, which may stem the tide of the neuroendocrine cascade with inflammation and oxidative/nitrosative stress. I would like to see my belief in this pathway finally vindicated by the smart emerging generation of scientists who have at their disposal the tools to unravel these new and intriguing complexities.

The relationship of diabetes and its treatment to cancer, $\mathrm{C}$ cell hyperplasia, bladder cancer, and pancreatic and breast cancer is another area that needs major focus
(Taubes, 2012). The ability of biguanides to combat both diabetes and cancer suggests that these intriguing metabolic partners ought to be explored further and we will see the emergence of a dual class of agents that can mitigate both conditions.

Another topic of particular interest is the application of new technologies for the delivery of insulin and other possible peptides and for continuous monitoring and closing the loop of the artificial pancreas. Islet regeneration and replication, as well as novel techniques for isolating and expansion of islets, will prove welcome research, as well as studies on oxidative/nitrosative stress and inflammation and the identification of novel therapies to combat these. From a clinical perspective, this includes the use of modern technology for ways and means of information transfer and studies, which enhance outreach and promote self management (Basevi et al., 2011). The field needs a means of quantification of quality of life and its enhancement (Vinik and Zhang, 2007), including the comorbidities of diabetes such as anxiety, depression, and sleep disturbance.

The ultimate goal of Frontiers in Diabetes is to provide a vehicle for accelerating communication between scientists and clinicians globally and to provide a platform capable of short-circuiting the onerous aspects of traditional publication systems. This will serve to enhance the quality of research in the basic science and clinical care of diabetes, and to encourage the merging of these disciplines into translational research, creating an extended Frontiers family of clinical scientists globally sharing our mission to cure diabetes and prevent its complications.

\section{REFERENCES}

Basevi, V., Di, M. S., Morciano, C., Nonino, F., and Magrini, N. (2011). Comment on: American Diabetes Association. Standards of medical care in diabetes-2011. Diabetes Care 2011;34(Suppl. 1):S11-S61. Diabetes Care 34, e53.

Bennett, W. L., Odelola, O. A., Wilson, L. M., Bolen, S., Selvaraj, S., Robinson, K. A., Bass, E. B., and Puhan, M. A. (2012). Evaluation of guideline recommendations on oral medications for type 2 diabetes mellitus: a systematic review. Ann. Intern. Med. 156, 27-36.

Bergenstal, R. M. (2006). Treatment models from the International Diabetes Center: advancing from oral agents to insulin therapy in type 2 diabetes. Endocr. Pract. 12(Suppl. 1), 98-104.

Blonde, L. (2005). Current challenges in diabetes management. Clin. Cornerstone 7(Suppl. 3), S6-S17.

Boussageon, R., Bejan-Angoulvant, T., Saadatian-Elahi, M., Lafont, S., Bergeonneau, C., Kassaï, B., Erpeldinger 
S., Wright, J. M., Gueyffier, F., and Cornu, C. (2011). Effect of intensive glucose lowering treatment on all cause mortality, cardiovascular death, and microvascular events in type 2 diabetes: meta-analysis of randomised controlled trials. BMJ 343, d4169.

Brown, J. B., Nichols, G. A., and Perry, A. (2004). The burden of treatment failure in type 2 diabetes. Diabetes Care 27, 1535-1540.

Donnan, P. T., MacDonald, T. M., and Morris, A. D. (2002). Adherence to prescribed oral hypoglycaemic medication in a population of patients with Type 2 diabetes: a retrospective cohort study. Diabet. Med. 19, 279-284.

Holman, R. R., Paul, S. K., Bethel, M. A., Matthews, D. R., and Neil, H.A. (2008). 10-Year follow-up of intensive glucose control in type 2 diabetes. N. Engl. J. Med. 359, 1577-1589.

McDonald, H. P., Garg, A. X., and Haynes, R. B. (2002). Interventions to enhance patient adherence to medication prescriptions: scientific review. JAMA 288 , 2868-2879.

Nathan, D. M., Buse, J. B., Davidson, M. B., Ferrannini, E., Holman, R. R., Sherwin, R., Zinman, B., American Diabetes Association, and European Association for Study of Diabetes. (2009). Medical management of hyperglycemia in type 2 diabetes: a consensus algorithm for the initiation and adjustment of therapy: a consensus statement of the American Diabetes
Association and the European Association for the Study of Diabetes. Diabetes Care 32, 193-203.

Osterberg, L., and Blaschke, T. (2005). Adherence to medication. N. Engl. J. Med. 353, 487-497.

Piette, J. D., Heisler, M., and Wagner, T. H. (2004). Problems paying out-of-pocket medication costs among older adults with diabetes. Diabetes Care 27, 384-391.

Power, C., and Rasko, J.E. (2011). Promises and challenges of stem cell research for regenerative medicine. Ann. Intern. Med. 155, 706-713.

Rakel, R. E. (2009). Improving patient acceptance and adherence in diabetes management: a focus on insulin therapy. Adv. Ther. 26, 838-846.

Shah, B. R., Hux, J. E., Laupacis, A., Zinman, B., and van Walraven, C. (2005). Clinical inertia in response to inadequate glycemic control: do specialists differ from primary care physicians? Diabetes Care 28, 600-606.

Taubes, G. (2012). Cancer research. Unraveling the obesity-cancer connection. Science 335, 28-30, 32.

Van Gaal, L. F., and De Leeuw, I. H. (2003). Rationale and options for combination therapy in the treatment of Type 2 diabetes. Diabetologia 46(Suppl. 1), M44-M50.

Vinik,A. (2007). Too many notes: up and down the scales of diabetes therapy. Clin. Ther. 29, 1227-1235.

Vinik, A. I., Maser, R. E., and Ziegler, D. (2011). Autonomic imbalance: prophet of doom or scope for hope? Diabet. Med. 28, 643-651.
Vinik, A. I., and Zhang, Q. (2007). Adding insulin glargine versus rosiglitazone: health-related quality-of-life impact in type 2 diabetes. Diabetes Care 30, 795-800.

Wing, R. R., Lang, W., Wadden, T.A., Safford, M., Knowler, W. C., Bertoni, A. G., Hill, J. O., Brancati, F. L., Peters, A., Wagenknecht, L., and Look AHEAD Research Group. (2011). Benefits of modest weight loss in improving cardiovascular risk factors in overweight and obese individuals with type 2 diabetes. Diabetes Care 34, 1481-1486.

Zoungas, S., Patel, A., Chalmers, J., de Galan, B. E., Li, Q., Billot, L., Woodward, M., Ninomiya, T., Neal, B., MacMahon, S., Grobbee, D. E., Kengne, A. P., Marre, M., Heller, S., and ADVANCE Collaborative Group. (2010). Severe hypoglycemia and risks of vascular events and death. N. Engl. J. Med. 363, 1410-1418.

Received: 01 February 2012; accepted: 14 February 2012; published online: 01 March 2012.

Citation: Vinik A (2012) Grand challenges in diabetes. Front. Endocrin. 3:37. doi: 10.3389/fendo.2012.00037

This article was submitted to Frontiers in Diabetes, a specialty of Frontiers in Endocrinology.

Copyright $(2012$ Vinik. This is an open-access article distributed under the terms of the Creative Commons Attribution Non Commercial License, which permits non-commercial use, distribution, and reproduction in other forums, provided the original authors and source are credited. 